\title{
POLÍTICAS DE EDUCAÇÃO NÃO-FORMAL NAS AMÉRICAS, ÁFRICA E ÁSIA: CONTRIBUIÇÕES PARA A CONSTRUÇÃO DO CAPITAL SOCIAL E HUMANO.
}

\author{
Eduard Angelo Bendrath
}

Programa de Pós Graduação em Educação - Doutorado. Universidade Estadual Paulista - UNESP/FCT. E-mail: bendrath@ig.com.br. Agência de Fomento: CAPES

\section{RESUMO}

O presente estudo está vinculado ao Programa de Pós-graduação em Educação da Faculdade de Ciências e Tecnologia da Universidade Estadual Paulista, campus de Presidente Prudente, e seu objetivo foi analisar as políticas de educação não-formal desenvolvidas em 18 países de 3 continentes e verificar de que forma elas estão relacionadas com os movimentos de desenvolvimento social e econômico dos países contribuindo para a ampliação do estoque de capital social e humano tendo como referência as teorias de Putnam, Coleman e Schultz. Como procedimento foi adotado o princípio de análise em educação comparada descrito na literatura e os dados dos países foram coletados junto ao banco de dados da UNESCO em Paris a partir de seus relatórios técnicos. Os resultados indicaram flutuações de interesses e objetivos que estão orientados por matrizes culturais e econômicas de cada país, sendo a educação não-formal uma ferramenta de destaque para resolução emergencial de problemas pontuais de cada sociedade. Palavras Chave: Educação não-formal; Políticas Públicas; Capital Social; Capital Humano, UNESCO

\section{INTRODUÇÃO}

Ainda são poucos os estudos que visam compreender o papel de modelos de educação não-formal dentro de sistemas educacionais e seus impactos nos processos de desenvolvimento social e econômico em contextos variados. As análises da UNESCO sobre a área trazem reflexões profundas para um novo panorama educacional que não se restringe única e exclusivamente às orientações definidas pela educação formal e seus ciclos de aprendizagem pré-elaborados.

De acordo com a própria UNESCO (2011) o conceito de educação não-formal é entendido como toda atividade educativa organizada que não corresponde exatamente à definição de educação formal. Entende-se que a educação não-formal pode ter seu lugar tanto dentro como fora das instituições educativas estando acessível para pessoas de todas as idades. Esse conceito é reforçado pelos argumentos de Hoopers (2006), Gohn (2008) e Torres (1992) que observam no modelo de educação não-formal uma nova possibilidade de mudança de paradigma.

No entanto, destaca-se que a base epistemológica de origem do conceito de educação nãoformal está diretamente relacionado com as possibilidades de ampliação de recursos humanos aptos aos desafios da economia contemporânea. O conceito inicial do termo, proposto por P.H. Coombs (1976) chama a atenção para mudanças tanto nos processos pedagógicos de ensino- 
aprendizagem, quanto para a organização dos sistemas educativos. Para o autor, as prioridades e metas devem fazer parte desse cotidiano, adequando o princípio da formação às necessidades de mão-de-obra, qualidade e custo. Nesse ínterim, a educação não-formal, chamada até então por ele de "ensino não-formal" aparece como um conjunto de atividades que constituem importante complemento para o ensino formal. O modelo de aprendizagem não-formal defendido por Coombs estava diretamente associado a um modelo de educação permanente, que décadas mais tarde seria aprimorado por Delors (1996) e definido como educação ao longo da vida.

Essa abordagem proposta por Coombs adequa-se ao disposto anteriormente por Theodore Schultz na década de 1950 e 1960 em sua teoria do capital humano na qual defendia que a ampliação do capital ${ }^{1}$ está diretamente representada pela mão de obra qualificada, apta a responder com eficiência as constantes mudanças e demandas impostas pelo mercado, sendo capaz de obter uma força produtiva que gera riqueza, desenvolvimento e equilíbrio social. Nessa perspectiva Schultz (1961) analisou o processo de recuperação dos países no pós-guerra, constatando que uma população mais educada torna-se uma sociedade mais produtiva, o que ele chamou na época de "capital educacional". Assim, o princípio fundamental da teoria do capital humano estaria na sua multiplicidade de fatores associados que não pode ser resumido em uma única regra universalmente aplicável.

Da mesma forma em que o modelo educacional não-formal apresenta nuances de alinhamento ao disposto na teoria do capital humano, podemos observar uma aproximação de suas ações pontuais com objetos que estão direcionados a uma abordagem relacionada ao capital social proposto por Putnam (2006) e Coleman (1988), especialmente quando programas e projetos de educação não-formal visam a recuperação social de comunidades economicamente desfavorecidas. Dessa maneira o capital social pode ser entendido como um conceito relativo ao benefício das múltiplas relações sociais agregadas a um sistema de confiança mútuo, garantindo cooperação e tratamento igual entre indivíduos ou grupos, de acordo com os interesses e objetivos específicos em comum dentro de uma sociedade. Nessa perspectiva Coleman (1988) defende que o conceito de capital social está no fato de cada ator ter o controle sobre certos recursos e interesses sobre certos recursos e eventos, o que pode ser traduzido como multiplas relações de interesses que se fortalecem via ações mútuas de reciprocidade, dentre elas, ambientes de aprendizagens não formais.

\footnotetext{
${ }^{1}$ Schultz fundamentou seu discurso pautado na idéia de que o capital humano deve ser observado a partir de outra perspectiva, diferenciando-o dos outros modelos de acumulação capitalista. Segundo o autor, o capital humano tem sua essência no homem e suas experiências, diferentemente do capital físico, capital de giro, que possui sua essência nos modos de acumulação diretamente cambiável por meio do processo de atribuição de "valor monetário".
} 
Dessa forma, o objetivo dessa pesquisa foi investigar a dinâmica das políticas de educação não-formal em 18 países de 3 continentes contribuindo para a compreensão de seus indicativos de aplicabilidade no processo de desenvolvimento econômico e social de um país.

\section{METODOLOGIA}

Essa pesquisa pode ser classificada como sendo de caráter qualitativo, com uma abordagem centrada em análise de políticas públicas com foco em avaliação de processo conforme proposto por Figueiredo e Figueiredo (1986).

Como procedimento de coleta de dados, tomou-se como referência a obtenção de dados provenientes de relatórios técnicos dispostos na base de dados da UNESCO em Paris, sendo encontrados relatórios oficiais de 18 países sobre suas políticas de educação não-formal. As bases de dados usadas foram UNESCODoc e UNESCO Institute of Statistics (UIS). Os relatórios técnicos obtidos para análise foram os seguintes: 2008/ED/EFA/MRT/PI/28, 2008/ED/EFA/MRT/PI/26, 2008/ED/EFA/MRT/PI/64, 2008/ED/EFA/MRT/PI/49, 2008/ED/EFA/MRT/PI/45, 2008/ED/EFA/MRT/PI/63, 2008/ED/EFA/MRT/PI/6, 2008/ED/EFA/MRT/PI/36, 2008/ED/EFA/MRT/PI/56, 2008/ED/EFA/MRT/PI/52, 2008/ED/EFA/MRT/PI/73, 2008/ED/EFA/MRT/PI/31, sendo o relatório 2008/ED/EFA/MRT/PI/55 uma compilação de mais 6 países em um único documento.

Os países cujos relatórios possibilitaram uma análise sobre o panorama das políticas de educação não-formal foram: Afeganistão, África do Sul, Bangladesh, Botsuana, Brasil, Camboja, China, Egito, Etiópia, Filipinas, Gana, Honduras, Índia, Indonésia, Laos, Malawi, Mali e México, e o critério de inclusão deu-se exclusivamente sobre a existência de dados provenientes de documentação oficial da UNESCO sobre o tema.

Para a análise dos dados coletados tomou-se como referência as abordagens de educação comparada dispostos na literatura, em relação aos seus objetivos, possibilidades e aplicabilidades. De acordo com Lourenço Filho (2004) nos estudos comparativos, os problemas de educação são examinados numa grande escala, social, política, cultural, a escala do que temos chamado macroeducação. Eles permitem apreciar as duas faces correspondentes às categorias de conceitos dantes referidos: uma de ideais, aspirações e valores, em planos e programas; e outra de realidades vistas como trabalho que já se tenha produzido e cujos efeitos possam ser contados, medidos, analisados. 


\section{RESULTADOS}

O acesso aos relatórios da UNESCO possibilitou compreender o interesse da organização em analisar o desenvolvimento de políticas de educação não-formal em países em processo de desenvolvimento, corroborando para a tese de que esse modelo educacional enquadra-se como ferramenta de recuperação social e econômica em momentos pontuais. Não foram encontrados relatórios produzidos pela UNESCO que apresentassem dados relacionados a países europeus e os demais documentos limitam as análises no continente americano a países de origem latina como Brasil, México e Honduras.

Os dados consolidados de 2011 do banco de dados da UNESCO apresentam um panorama geral (Tabela 1) que indica diferenças de desenvolvimento em relação aos países e seus continentes, o que indicaria os rumos de políticas nacionais que trilhassem medidas de correção e avanço social e econômico. As principais diferenças concentram-se no percentual da população rural, muito mais acentuado nos paises analisados da Ásia e na África do que nos países Americanos, assim também como o IDH, PIB per capita e expectativa de vida que mantiveram o mesmo padrão.

Tabela 1. Panorama de indicadores econômicos e sociais dos países analisados

\begin{tabular}{|c|c|c|c|c|c|c|}
\hline \multirow{2}{*}{$\begin{array}{c}\text { País / } \\
\text { Continente }\end{array}$} & \multirow[b]{2}{*}{ População } & $\begin{array}{c}\text { Expectativa de } \\
\text { Vida }\end{array}$ & \multirow{2}{*}{\begin{tabular}{|c|} 
PIB per Capita \\
Valores em US\$ \\
\end{tabular}} & \multirow{2}{*}{$\begin{array}{c}\text { IDH } \\
\text { Escala PNUD }\end{array}$} & \multirow{2}{*}{\begin{tabular}{|c|}
$\begin{array}{c}\text { Crescimento } \\
\text { Populacional }\end{array}$ \\
$\%$ ao ano \\
\end{tabular}} & \multirow{2}{*}{$\begin{array}{c}\begin{array}{c}\text { População } \\
\text { Rural }\end{array} \\
\%\end{array}$} \\
\hline & & Idade & & & & \\
\hline \multicolumn{7}{|c|}{ AMÉRICA (Norte, Central e do Sul) } \\
\hline Brasil & 193.946 .886 & 73 & $11.640,00$ & 0,730 & 0,9 & 15 \\
\hline Honduras & 7.754 .687 & 73 & $4.047,00$ & 0,632 & 2,0 & 48 \\
\hline México & 114.793 .341 & 77 & $16.588,00$ & 0,775 & 1,2 & 22 \\
\hline $\begin{array}{l}\text { Sub } \\
\text { Total/Média }\end{array}$ & 316.494.914* & 74.3 & $10.758,00$ & 0,666 & 1,3 & 28,3 \\
\hline \multicolumn{7}{|l|}{ AFRICA } \\
\hline África do Sul & 50.459 .978 & 53 & $10.960,00$ & 0,629 & 1,2 & 38 \\
\hline Botsuana & 2.030 .738 & 53 & $14.706,00$ & 0,634 & 1,2 & 38 \\
\hline Egito & 82.536 .770 & 73 & $6.281,00$ & 0,662 & 1,7 & 56 \\
\hline Etiópia & 84.734 .262 & 59 & $1.109,00$ & 0,396 & 2,1 & 83 \\
\hline Gana & 24.965 .816 & 64 & $1.871,00$ & 0,558 & 2,3 & 48 \\
\hline Malawi & 15.380 .888 & 54 & 893,00 & 0,344 & 3,0 & 65 \\
\hline Mali & 15.839 .538 & 51 & $1.091,00$ & 0,418 & 3,2 & 84 \\
\hline $\begin{array}{l}\text { Sub } \\
\text { Total/Média }\end{array}$ & 275.947.990* & 58,1 & $5,273,00$ & 0,520 & 2,1 & 58,8 \\
\hline \multicolumn{7}{|l|}{ ASIA } \\
\hline Afeganistão & 32.358 .260 & 49 & $1.139,00$ & 0,374 & 2,7 & 76 \\
\hline Bangladesh & 150.493 .658 & 69 & $1.177,00$ & 0,515 & 1,2 & 72 \\
\hline
\end{tabular}




\begin{tabular}{|l|r|r|r|r|r|r|}
\hline Camboja & 14.305 .183 & 63 & $2.358,00$ & 0,543 & 1,2 & 80 \\
\hline China & 1.347 .565 .32 & 73 & $8.400,00$ & 0,699 & 0,5 & 49 \\
\hline Filipinas & 94.852 .030 & & & & & \\
\hline Índia & 1.241 .491 .96 & 69 & $4.119,00$ & 0,654 & 1,7 & 51 \\
\hline Indonésia & 242.325 .638 & 65 & $3.650,00$ & 0,554 & 1,4 & 69 \\
\hline Laos & 6.288 .037 & 69 & $4.636,00$ & 0,629 & 1,0 & 49 \\
\hline Sub & 3.129 .680 .09 & 67 & $2.790,00$ & 0,543 & 1,4 & 66 \\
\hline Total/Média & $0 *$ & 65,5 & $3.533,00$ & 0,625 & 1,3 & 64 \\
\hline TOTAL/MÉDIA & $\mathbf{3 . 7 2 2 . 1 2 2 . 9 9}$ & $4 *$ & & & & \\
\hline
\end{tabular}

Fonte: Instituto de Estatística da UNESCO (UIS), 2011

Em relação aos sistemas educacionais nos referidos países, constatou-se a ausência de informações detalhadas sobre a aplicação de recursos destinados à educação tomando como referência o Produto Interno Bruto (PIB). Foi possível observar que em 5 países (Tabela 2) a população em idade escolar referente ao ensino secundário já ultrapassou a população em idade escolar do ensino primário, o que pode indicar para os próximos anos a inversão de políticas de ampliação de vagas e melhoria da qualidade da educação, que, desde o marco de Jomtiem (1990) e Dakar (2000) vem reforçando a necessidade de maiores investimentos nos primeiros anos de escolarização.

Tabela 2. População em Idade Escolar e Investimento do PIB em educação

\begin{tabular}{|c|c|c|c|c|}
\hline \multirow{2}{*}{$\begin{array}{l}\text { País / } \\
\text { Continente }\end{array}$} & \multirow{2}{*}{$\begin{array}{l}\text { População } \\
\text { Nacional }\end{array}$} & $\begin{array}{c}\text { População em Idade } \\
\text { Escolar }\end{array}$ & $\begin{array}{c}\text { População em Idade } \\
\text { Escolar }\end{array}$ & PIB Investido \\
\hline & & Primário & Secundário & $\%$ \\
\hline \multicolumn{5}{|c|}{ AMÉRICA (Norte, Central e do Sul) } \\
\hline Brasil & 193.946 .886 & Não divulgado & Não divulgado & 5,3 \\
\hline Honduras & 7.754 .687 & 1.103 .763 & 895.932 & Não divulgado \\
\hline México & 114.793.341 & 13.227.296 & 13.048 .567 & Não divulgado \\
\hline \multicolumn{5}{|l|}{ AFRICA } \\
\hline África do Sul & 50.459 .978 & 7.053 .390 & 4.950 .184 & Não divulgado \\
\hline Botsuana & 2.030 .738 & 297.540 & 217.950 & Não divulgado \\
\hline Egito & 82.536 .770 & 10.032 .719 & 9.483 .270 & Não divulgado \\
\hline Etiópia & 84.734 .262 & 13.541 .946 & 12.086 .560 & Não divulgado \\
\hline Gana & 24.965 .816 & 3.598 .472 & 3.694 .842 & 8,2 \\
\hline Malawi & 15.380 .888 & 2.522 .561 & 2.154 .870 & 5,4 \\
\hline Mali & 15.839 .538 & 2.589 .583 & 2.079 .922 & 4,7 \\
\hline
\end{tabular}




\begin{tabular}{|l|r|r|r|r|}
\hline \multicolumn{1}{|l|}{ ASIA } \\
\hline Afeganistão & 32.358 .260 & 5.541 .751 & 4.663 .132 & Não divulgado \\
\hline Bangladesh & 150.493 .658 & Não divulgado & 22.241 .120 & Não divulgado \\
\hline Camboja & 14.305 .183 & 1.770 .344 & 2.010 .235 & Não divulgado \\
\hline China & 1.347 .565 .32 & 88.186 .917 & 119.773 .195 & Não divulgado \\
& 4 & 13.311 .803 & & \\
Filipinas & 94.852 .030 & 123.615 .820 & 170.731 .718 & Não divulgado \\
\hline Índia & 1.241 .491 .96 & 0.196 .948 & Não divulgado \\
\hline Indonésia & 242.325 .638 & 25.907 .660 & 25.731 .836 & 2,8 \\
Laos & 6.288 .037 & 714.365 & 1.070 .562 & Não divulgado \\
TOTAL & $\mathbf{3 . 7 2 2 . 1 2 2 . 9 9}$ & $\mathbf{4 1 3 . 0 1 5 . 9 3 0}$ & $\mathbf{4 0 3 . 0 3 0 . 8 4 3}$ & Média 5,28\% \\
\hline
\end{tabular}

Fonte: Instituto de Estatística da UNESCO (UIS), 2011

Em relação às políticas de educação não-formal nos 18 países da pesquisa, observou-se um consenso referente a participação de agentes externos na parceria referentes à formulação e implementações da ações nesse campo junto aos governos. Esses agentes externos foram caracterizados em duas vertentes: 1) Agências oficiais: organismos Internacionais, oriundos das ramificações dos setores e departamentos da ONU, com especial destaque para a UNESCO, UNICEF, Banco Mundial, FMI, e organismos ligados a Estados nacionais, como o caso dos Fundos de Desenvolvimento Internacional do Japão, Suécia e Bélgica, e 2) Organizações NãoGovernamentais nacionais e locais, oriundas dos próprios países.

Essa participação dos agentes externos nas políticas de educação não-formal nos países acontece via financiamento direto, com aporte de recursos financeiros e em alguns casos de recursos humanos para o desenvolvimento dos programas de projetos, e/ou através de suporte e assessoria técnica na condução da organização, definição e acompanhamento do cumprimento das metas pré-estabelecidas.

A observação dos programas e projetos de educação não-formal corroborados pelas políticas públicas dos referidos países foram classificados em 5 vertentes (Quadro 1) que se enquadram nos pressupostos da própria UNESCO para os princípios característicos do modelo não-formal com aporte ao conceito de educação ao longo da vida. 
Quadro 1. Políticas de educação não-formal e a relação com a formação do capital humano e social

\begin{tabular}{|c|c|c|c|}
\hline Categoria & Descrição & Capital Humano & Capital Social \\
\hline Aprendizagem & $\begin{array}{l}\text { Faz referência ao uso do sistema } \\
\text { não-formal de educação para a } \\
\text { obtenção de padrões definidos } \\
\text { pela educação básica. Incluem- } \\
\text { se nessa categoria as políticas de } \\
\text { alfabetização, e educação de } \\
\text { jovens e adultos. }\end{array}$ & $\begin{array}{l}\text { Formação e } \\
\text { preparação para os } \\
\text { desafios impostos } \\
\text { pela sociedade e } \\
\text { mercado. } \\
\text { Preparação para a } \\
\text { vida. }\end{array}$ & ---- \\
\hline $\begin{array}{l}\text { Habilidades para } \\
\text { Vida }\end{array}$ & $\begin{array}{l}\text { Faz referência a ações que visam } \\
\text { desenvolver habilidades } \\
\text { pessoais com intuito do } \\
\text { fortalecimento individual e } \\
\text { coletivo de uma determinada } \\
\text { comunidade. Incluem-se nessa } \\
\text { categoria políticas de } \\
\text { qualificação e recolocação } \\
\text { profissional. }\end{array}$ & $\begin{array}{l}\text { Readequação de } \\
\text { formação e } \\
\text { empregabilidade } \\
\text { para } \\
\text { enquadramento } \\
\text { técnico } \\
\text { profissional. }\end{array}$ & $\begin{array}{lr}\text { Utilização } & \text { de } \\
\text { habilidades } & \\
\text { individuais } & \text { na } \\
\text { resolução } & \text { de } \\
\text { problemas } & \\
\text { comunitários. } & \\
\text { Fortalecimento } & \text { de } \\
\text { competências } & \text { e } \\
\text { autoestima. } & \end{array}$ \\
\hline $\begin{array}{ll}\text { Vida } & \text { em } \\
\text { Comunidade } & \end{array}$ & $\begin{array}{l}\text { Faz referência às ações de } \\
\text { desenvolvimento comunitário e } \\
\text { fortalecimento da vida coletiva. } \\
\text { Incluem-se nessa categoria } \\
\text { ações de aprendizagem em } \\
\text { áreas como saúde e prevenção, } \\
\text { nutrição e alimentação, cultura } \\
\text { da paz e convívio social. }\end{array}$ & & $\begin{array}{l}\text { Ampliação da rede } \\
\text { de relacionamento } \\
\text { social e geração de } \\
\text { confiança } \\
\text { comunitária. }\end{array}$ \\
\hline $\begin{array}{l}\text { Desenvolvimento } \\
\text { Comunitário }\end{array}$ & $\begin{array}{l}\text { Faz referência à políticas que } \\
\text { favoreçam o desenvolvimento } \\
\text { econômico e social de } \\
\text { determinada comunidade. } \\
\text { Incluem-se nessa categoria } \\
\text { ações de expansão de infra- } \\
\text { estrutura, geração de renda e } \\
\text { empreendedorismo. }\end{array}$ & $\begin{array}{l}\text { Preparação } \\
\text { individual para o } \\
\text { mercado } \\
\text { trabalho de } \\
\text { expansão da rede } \\
\text { de negócios. }\end{array}$ & $\begin{array}{l}\text { Fortalecimento das } \\
\text { ações comunitárias } \\
\text { via processos de } \\
\text { geração de renda e } \\
\text { suporte de infra- } \\
\text { estrutura física e } \\
\text { social. }\end{array}$ \\
\hline $\begin{array}{l}\text { Treinamento } \\
\text { Vocacional }\end{array}$ & $\begin{array}{l}\text { Faz referência à políticas de } \\
\text { especialização profissional, } \\
\text { orientadas pelos interesses } \\
\text { nacionais em setores críticos. } \\
\text { Incluem-se nessa categoria } \\
\text { ações de educação não-formal } \\
\text { com vistas à formação laboral } \\
\text { técnica. }\end{array}$ & $\begin{array}{lr}\text { Formação } & \text { técnica } \\
\text { para } & \text { pontos } \\
\text { críticos } & \text { do } \\
\text { mercado } & \text { de } \\
\text { trabalho. } & \end{array}$ & \\
\hline
\end{tabular}

Fonte: Pesquisa autor 
A análise de tais ações, políticas, programas e projetos implantados nos últimos anos nos 18 países traz um panorama real de como a educação não-formal está sendo observada e entendida em contextos diferentes com objetivos diversos, o que pode, a partir de uma compreensão macro-educacional contribuir para entender o papel de tais políticas no cenário não só educacional, mas também de desenvolvimento econômico e social.

De uma forma geral, nota-se a utilização de políticas de educação não-formal relacionadas às necessidades de recuperação em determinados aspectos (em especial alfabetização, geração de renda e qualificação profissional), cujo ambiente formal não é capaz de congregar ou oferecer respostas imediatas aos problemas elencados. No mais, as políticas de educação não-formal fortalecem o sistema formal ao oferecer complementação às ações de aprendizagem. O Quadro 2 apresenta um panorama sintético das políticas encontradas nos 18 países da pesquisa.

Quadro 2. Panorama das Políticas de Educação não-formal.

\begin{tabular}{|l|c|c|c|c|c|}
\hline \multirow{2}{*}{ PAÍs } & \multicolumn{5}{|c|}{ CATEGORIAS } \\
\cline { 2 - 6 } & Aprendizagem & $\begin{array}{c}\text { Habilidades } \\
\text { para a vida }\end{array}$ & $\begin{array}{c}\text { Vida em } \\
\text { Comunidade }\end{array}$ & $\begin{array}{c}\text { Desenvolvimento } \\
\text { Comunitário }\end{array}$ & $\begin{array}{c}\text { Treinamento } \\
\text { Vocacional }\end{array}$ \\
\hline Afeganistão & $\mathrm{X}$ & - & - & $\mathrm{X}$ & - \\
\hline África do Sul & $\mathrm{X}$ & - & - & $\mathrm{X}$ & $\mathrm{X}$ \\
\hline Bangladesh & $\mathrm{X}$ & $\mathrm{X}$ & $\mathrm{X}$ & $\mathrm{X}$ & - \\
\hline Botsuana & $\mathrm{X}$ & - & - & $\mathrm{X}$ & $\mathrm{X}$ \\
\hline Brasil & $\mathrm{X}$ & $\mathrm{X}$ & $\mathrm{X}$ & $\mathrm{X}$ & $\mathrm{X}$ \\
\hline Camboja & - & $\mathrm{X}$ & - & $\mathrm{X}$ & - \\
\hline China & $\mathrm{X}$ & - & - & - & $\mathrm{X}$ \\
\hline Egito & $\mathrm{X}$ & $\mathrm{X}$ & $\mathrm{X}$ & - & - \\
\hline Etiópia & $\mathrm{X}$ & $\mathrm{X}$ & - & - & $\mathrm{X}$ \\
\hline Filipinas & $\mathrm{X}$ & $\mathrm{X}$ & $\mathrm{X}$ & - & $\mathrm{X}$ \\
\hline Gana & $\mathrm{X}$ & $\mathrm{X}$ & $\mathrm{X}$ & - & $\mathrm{X}$ \\
\hline Honduras & $\mathrm{X}$ & $\mathrm{X}$ & $\mathrm{X}$ & - & - \\
\hline Índia & $\mathrm{X}$ & - & $\mathrm{X}$ & - & - \\
\hline Indonésia & $\mathrm{X}$ & - & $\mathrm{X}$ & - & $\mathrm{X}$ \\
\hline Laos & $\mathrm{X}$ & $\mathrm{X}$ & - & - & - \\
\hline Malawi & $\mathrm{X}$ & $\mathrm{X}$ & $\mathrm{X}$ & - & - \\
\hline Mali & $\mathrm{X}$ & - & $\mathrm{X}$ & $\mathrm{X}$ & \\
\hline México & - & $\mathrm{X}$ & - & & \\
\hline Fonte: & & & & - \\
\hline
\end{tabular}

Fonte: Pesquisa autor.

\section{DISCUSSÃO}

Os dados encontrados fortalecem o discurso oficial da UNESCO que reforça a tese de uma amplitude de ações em que a educação não-formal pode atuar, com destaque para os processos 
de aproximação com a educação básica, o mundo do trabalho e as competências gerais para a vida. Dessa forma tomam-se como pressuposto dois indicadores a serem considerados no planejamento de políticas para a área: 1) oportunidades educacionais fora do sistema formal, sendo definidas pelo governo e por doadores e apoiadores; 2) necessidade de manutenção e sentido de inovação para uma educação com vistas a um modo flexível de aprendizagem. Tais indicadores são influenciados pelas necessidades prementes dos países em assegurar a formação do capital humano e social necessários para o desenvolvimento nacional, o que pode ocorrer de formas diversas levando em consideração os aspectos econômicos, culturais e sociais de cada país.

A participação do modelo não-formal dentro dos sistemas oficiais de ensino (educação formal) é altamente recomendada pelos organismos internacionais que apóiam o argumento de que um sistema educacional complexo é capaz de lidar com modelos educacionais diversos, adaptando-se às especificidades de cada um a partir dos anseios e necessidades educacionais postos em cada localidade, sendo, portanto, não apenas possível a atuação concomitante entre ambos, mas favoravelmente recomendável.

A aproximação dessas políticas com as especificidades de preparação vocacional e técnica da população corrobora com os princípios de formação do capital humano, da mesma forma em que políticas de educação não-formal que favorecem a participação comunitária, seja via compartilhamento de experiências ou fomento à geração de renda, ampliam os laços sociais existentes gerando mecanismos democráticos de confiança e segurança, contribuindo para a formação do capital social tal qual o disposto na literatura.

O interesse internacional nessas ações, especialmente os oriundos das agências da própria ONU e dos bancos financiadores, colocam a educação não-formal em um patamar de destaque para o recebimento de verbas e fundos para administração, implantação e gerenciamento dos programas e projetos, o que também favorece a participação de entidades não governamentais (ONGs) na gestão desses recursos, e a minimização da participação do Estado no oferecimento desse modelo educacional.

\section{CONCLUSÕES}

As configurações encontradas nas políticas de educação não-formal nos 18 países analisados indicam que a implantação e gerenciamento das ações desse modelo educacional, estão amparados pelas necessidades emergentes de reestruturação social em países afetados por crises naturais, armadas, econômicas ou em fase de expansão do desenvolvimento sócio- 
econômico, como no caso da África do Sul, Brasil, China, México e Índia. Tais ações estão postas como meios efetivos e práticos de se obter, em curto espaço de tempo, respostas pontuais para problemas urgentes como desemprego e falta de qualificação para postos de trabalho, ambientes hostis e promoção de uma cultura de paz, e emancipação e desenvolvimento humano.

A implantação de modelos não-formais enfáticos e com maior direcionamento técnico de ações favorecem o construto de aproximação das comunidades, contribuindo para o aprimoramento pessoal individual, compartilhamento de ações comunitárias e suas relações decisórias em nível local, o que amplia de forma direta o capital social nas comunidades onde tais programas acabam sendo inseridos. No mesmo sentido tais medidas contribuem efetivamente para o desenvolvimento humano em seus aspectos cognitivos e técnico-laboral o que amplia a bagagem do capital humano que fica à disposição do sistema produtivo local, gerando forças de trabalho mais aptas a superar os desafios impostos pelas mudanças econômicas e tecnológicas no novo milênio.

Ao discutir os princípios do capital humano nessa pesquisa, reforçou-se a tese das cíclicas crises do capitalismo onde o processo educacional torna-se elo fundamental para as adequações necessárias de formação de acordo com cada panorama enfrentado. Da mesma forma, a teoria do capital social aproxima-se dos pressupostos ideológicos das políticas de educação não-formal na medida em que tenta estabelecer e fortalecer os elos de confiança social, minimizando potenciais riscos advindos da falta de coesão social.

\section{REFERÊNCIAS}

COOMBS, Philipe H. A crise mundial da educação. 1.ed. São Paulo: Perspectiva, 1976.

COLEMAN, James S. Social Capital in the Creation of Human Capital. The American Journal of Sociology, Vol. 94, Supplement: Organizations and Institutions: Sociological and Economic Approaches to the Analysis of Social Structure. (1988), pp. S95-S120.

DELORS, Jacques. Educação um Tesouro a Descobrir. Relatório para a UNESCO da Comissão Internacional sobre Educação para o século XXI. São Paulo, Cortez Editora. 1996, 288p.

FIGUEIREDO, Marcus Faria; FIGUEIREDO, Argelina Maria Cheibub. Avaliação política e Avaliação de políticas: um quadro de referência teórica. São Paulo: IDESP, 1986

GOHN, Maria da Glória. Educação Não-Formal e Cultura Política. 4.ed. São Paulo, Cortez. 2008.

HOOPERS, Win. Non-Formal Education and basic education reform: a conceptual review. International Institute for Educational Planning. UNESCO, Paris, 2006. 
Encontro de Ensino, Pesquisa e Extensão, Presidente Prudente, 21 a 24 de outubro, 2013

PUTNAM, Robert D. Comunidade e Democracia: a experiência da Itália moderna. 5a Ed. Rio de Janeiro, Editora FGV, 2006, 260p.

SCHULTZ, Theodore W. Investment in Human Capital. The American Economic Review. Vol. 51, Mar. 1961, p.1-17.

TORRES, Carlos Alberto. A Política da Educação Não-Formal na América Latina. Rio de Janeiro, Paz e Terra, 1992.

UNESCO. Guia para la Planificación de la Educación em Situações de Emergência y Reconstrucción. Instituto Internacional de Planificación de la Educación. Paris: UNESCO, 2011, $1206 p$. 